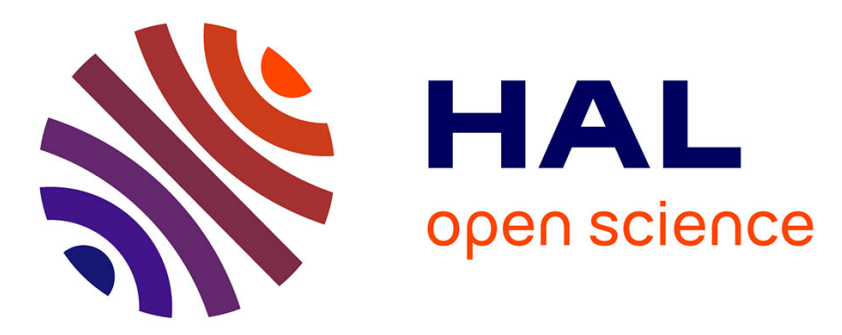

\title{
The Costs of Climate Change for the European Energy System, an Assessment with the POLES Model
}

\author{
Silvana Mima, Patrick Criqui
}

\section{To cite this version:}

Silvana Mima, Patrick Criqui. The Costs of Climate Change for the European Energy System, an Assessment with the POLES Model. Environmental Modeling \& Assessment, 2015, 20 (4), pp.303-319. 10.1007/s10666-015-9449-3 . hal-01149610

\section{HAL Id: hal-01149610 https://hal.univ-grenoble-alpes.fr/hal-01149610}

Submitted on 7 May 2015

HAL is a multi-disciplinary open access archive for the deposit and dissemination of scientific research documents, whether they are published or not. The documents may come from teaching and research institutions in France or abroad, or from public or private research centers.
L'archive ouverte pluridisciplinaire HAL, est destinée au dépôt et à la diffusion de documents scientifiques de niveau recherche, publiés ou non, émanant des établissements d'enseignement et de recherche français ou étrangers, des laboratoires publics ou privés. 


\title{
ÉCONOMIE DU DÉVELOPPEMENT DURABLE ET DE L'ÉNERGIE
}

\section{The Costs of Climate Change for the European Energy System, an Assessment with the POLES Model}

\author{
Silvana Mima \\ Patrick Criqui
}

Août 2014

Cahier de recherche EDDEN $n^{\circ} 11 / 2014$ 


\begin{abstract}
The paper presents a model-based approach describing the impacts of climate change on the European energy system. Existing analyses only estimate a limited range of climate impacts over a limited geographical area. Using the POLES model and the results from several climate models, the present paper quantifies the main impacts of climate change on the European energy sector, country by country, thus achieving progress in this direction. As far as energy demand is concerned, our main finding is that higher temperatures will mean that air-conditioning will consume more energy, reaching about 53 Mtoe by 2100 in a scenario with no strong emissions constraints (A1B). On the other hand less energy will be consumed for heating buildings, falling by about $65 \mathrm{M}$ toe per year. This represents a net decrease in energy consumption of about 12 Mtoe by 2100. On the supply side, more constrained and expensive operating conditions for electric power plants will result in lower electricity generation by thermal, nuclear and hydro-power plants, with a maximum decrease of about $200 \mathrm{TWh}$ in 2070 in the A1B scenario and 150 TWh in 2060 and 2080 for a low emissions scenario (E1). These effects vary a great deal across Europe and remain very dependent on the uncertainties affecting the results of the various climate models. This overall uncertainty may inhibit effective decisions. However the study offers insights not otherwise available without the full coverage of the energy system provided by POLES and climate features provided by climate models. The study identifies the main impacts of climate change in a strategic sector and provides an "order of magnitude" or "central trend" for these impacts, which might be useful in an adaptive policy of act, learn and then act again.
\end{abstract}

Keywords: climate impacts, climate change, costs of the impacts of climate change. 


\section{Introduction}

Weather and climate affect all major aspects of the energy sector, with major implications for energy demand and electricity generation. On the demand side, warmer winter temperatures in cold regions may reduce energy demand because less space-heating will be required. On the other hand, higher temperatures during summer months in warm regions will lead to more demand for electricity to run air-conditioners and refrigerators. Changes in precipitation will impact the potential of hydropower, positively or negatively depending on the region considered. Although the literature discussing these issues is becoming more substantial (Lehner et al., 2005; Wilbanks et al., 2008; Isaac et al., 2009; Mideksa et al., 2010; Petrick et al., 2010; Pilli-Sihvola et al., 2010; Mima et al., 2011). Only a few studies fully account for all the main climate impacts on the energy sector, covering all European countries. Existing studies evaluate only a limited range of climate impacts over limited geographical areas. Here we combine the results of several climate models with a version of the POLES model which has been specially developed to produce a broad picture of the most important climate impacts on energy supply and demand. Although we cover more impacts, in a more detailed geographical area than in previous studies, we do not claim to be complete. Research on this issue is quite challenging due to the lack of globally compiled datasets and the limited number of earlier studies. We started with a simple model and the figures reported should be treated as rough estimates of the nature and magnitude of impacts and their respective costs under average climate prospects as performed in the framework of the ClimateC ost project ${ }^{1}$. Moreover the results shed light on the relative importance of various impact drivers.

This study is in fact one of the first estimates to cover four types of climate impact on the energy system of each European country, broken down by energy source and tested for about 10 climatepolicy model runs and two types of scenario: a medium-high emissions scenario (A1B) and a low emissions mitigation scenario (E1) (see Nakicenovic et al, 2000). Because of its detailed representation of the energy system, the POLES model has been considered as suitable for calculating the major impacts of climate change on the energy sector through the development of soft links with climate models and some particular developments on:

- Changes in energy consumption for heating and cooling in the residential and tertiary sectors, according to different levels of climate change;

- Variations in resource availability for generating electricity with hydro plants;

- Increased cooling constraint impacting thermal-power generation, using fossil or nuclear fuel.

In this framework POLES provides insights into the interaction between climate change, energy use, and economics. The following section presents the model-based approach adopted for analyzing possible impacts of climate change. Results and a discussion of climate impacts on energy supply and

${ }^{1}$ ClimateC ost (Full Costs of Climate Change) is a Collaborative project funded by the European Commission under the Seventh Framework Programme. Grant agreement no.: 212774 
demand in the EU are presented in the third section. The fourth and final section summarizes some conclusions and possibilities for further extension.

\section{Measuring the impacts of the climate change on energy supply and demand with the POLES model}

\subsection{POLES model capability}

The Prospective Outlook for Long-term Energy Systems (POLES) model is a widely recognized partial equilibrium model, with a dynamic year-by-year simulation process, simulating the global energy system, from the present day till 2100. It is market-oriented, which means that market equilibrium prices drive the balance of supply and demand for each type of energy. Separate modules represent the national energy balances and the international markets for the world energy system in 57 countries and regions. In this framework, the EU is broken down into 27 Member States.

The model was developed by the EDDEN ${ }^{2}$ research group, in order to study international energy issues, technology development and global environmental strategies. Population and economic growth scenarios are exogenous variables. The structure of the POLES model is summarized in the following figure, showing interconnected modules (final demand, power generation including renewables, fossil fuel supply, international energy markets and prices), at the national, regional and global level (Criqui and Mima, 2006).

Figure 1: Structure of the POLES model

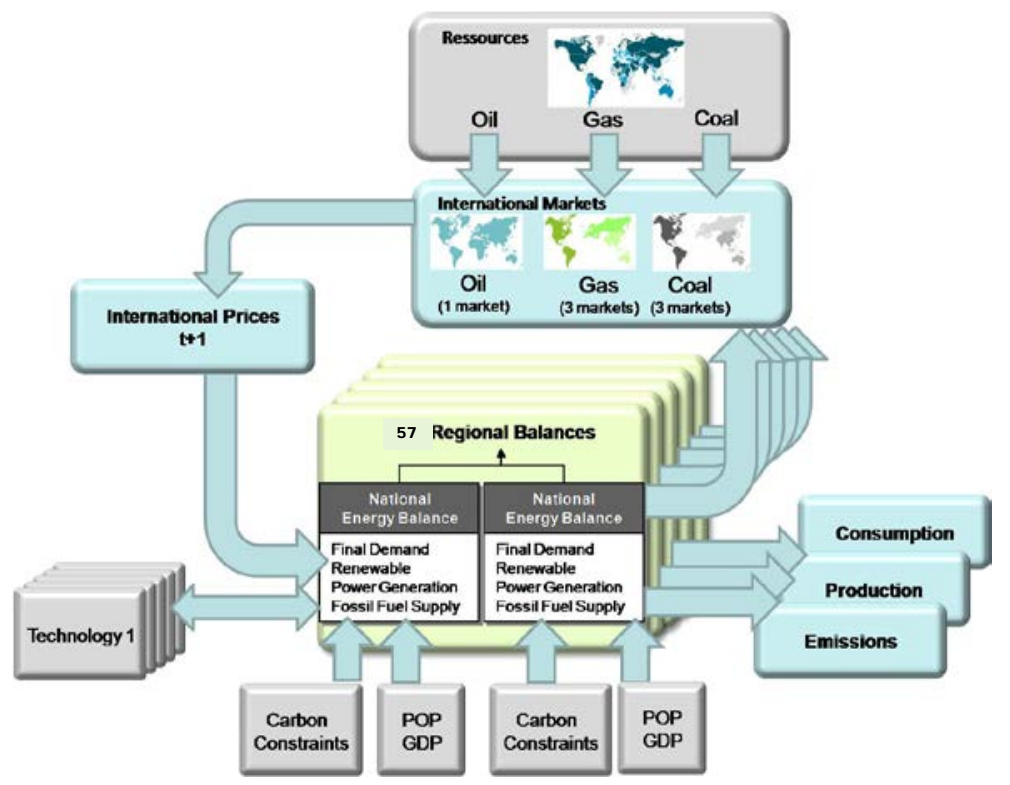

\footnotetext{
${ }^{2}$ Economie du développement durable et de l'énergie
} 
For each country or region, the POLES model implements three main modules that represent: i) final energy demand by fuel and main sector; ii) the electricity transformation system; and iii) the fossil fuel supply. Final energy demand by fuel is a function of three main determinants: short and long-term price effects, income or activity elasticities and an autonomous technological trend. For each period, the current demand for each individual fuel is reduced by a "scrapping factor" corresponding to the phasing-out rate of existing energy consuming equipment. The difference between total demand and the sum of "scrapped demands" being positive, the corresponding "gap" must be filled by new plants. Substitution between energy carriers takes place in the mix of these new plants, which depends on the relative total-user cost (investment and fuel cost) of the energy carriers. Demand for each fuel is therefore the sum of the scrapped demand and the share of the corresponding gap for the relevant sector. This allows for "putty-clay" behaviour in energy demand and substitutions. As the model also identifies separately electricity demand for non-heating purposes and for space-heating (including a share of electricity for heating), it is possible to identify the dual pressure exerted by climate change on the electricity sector during heat waves: electricity demand will rise due to extra consumption for cooling whereas, as we shall see below, thermal production may be constrained by the increased temperature of cooling water.

Once the demand by sector and by fuel has been calculated it is re-aggregated to calculate the total final energy demand by fuel, to become an input of the New and Renewable Energy and Electricity and Transformation System modules. After the necessary capacity expansion has been determined, the model then calculates the production mix of electricity from the given capacity structure by loading plants using a merit-order rule until demand is satisfied, while giving priority to plants with the lowest variable costs (not total costs). The power-production model distinguishes between "must-run" technologies: technologies with low (or zero) variable costs that will in any case deliver their production; and merit-order technologies with substantial variable production costs.

Several of the production options (e.g. hydro-electricity) are associated with resource and technical potentials which may limit their development. Use of hydroelectric plants typically depends on the water supply available, which varies considerably by region and season. Capacity expansion is thus a function of the technical potential and the gap between hydroelectric production costs and baseload-electricity prices. The POLES model produces robust economic assessments based on the costs of implementing new technologies, drawing on rigorous analys is of the engineering and scientific fundamentals.

Endogenous calculation of international energy prices is one of the key features of the POLES model. International price equations are at the very heart of the recursive process which accounts for the dynamics of the lagged adjustments of energy supply and demand. Domestic energy prices are deduced from the variation of import prices, derived in turn from variations in international prices. Consequently the model checks that subsidized domestic prices (lower than import prices) do not decrease when international prices decrease unless the latter fall below previous domestic prices. The model can also take account of alternative internal taxation policies on energy fuels. 
For this study, we draw on a set of new developments of the model designed to assess the potential impacts of climate change on energy demand and energy supply, through variations in temperature, precipitation or water regime.

\subsection{Improvements to the POLES model}

To investigate the changes in energy supply and demand due to long-term shifts in temperature and precipitation, we have added new drivers, such as temperature and precipitation changes, to the functional forms of the POLES model, also making allowance for the non-linear nature of their impacts on energy supply and demand. These non-linearities correspond to thresholds in the consequences of rising temperatures: consumption thresholds, with cooling equipment being installed and operated depending on the frequency and intensity of heat waves; production thresholds, when thermal generation must be stopped because the temperature of a plant's coolant exceeds established standards. Further additions to the model concern residential and tertiary demand for heating and cooling, and the supply of thermal, nuclear and hydro-electricity generation. The model accounts for interaction between these effects, reflecting the corresponding changes in generation costs, power plant installation and electricity prices.

\subsubsection{Modelling the impacts of climate change on heating demand}

In recent years some attention has focused on the relationship between residential and tertiary demand for heating energy and expected temperatures variations. Some contributions (Bigano et al., 2006; De Cian, 2007; Rongetal, 2007; Sailor, 2001) provide empirical analysis and fuel specific studies by country. The results of these studies can be used as data for impact analysis. Before 2009 such studies hardly existed at a global level. Isaac and Van Vuuren (2009) attempted to describe residential heating and cooling demand in the context of climate change for the first time at a global level, using simple relationships to describe heating and cooling demand. Petrick \& alii (2010) also investigated the links between rising global temperature and global energy use, based on a panel of 157 countries over three decades and limited to the residential sector. Compared to previous papers, they introduced better geographical coverage, including both developed and developing countries and they considered non-linearities in the impact of temperature on energy demand as well as temperatureincome interactions. They showed lower energy use with rising temperatures due to reduced demand for heating energy, with the gap compared to consumption "without climate change" increasing over time and with rising temperatures. Furthermore, they demonstrated that the response of energy use is affected by the level of temperature and income (Petrick \& alii (2010), p. 2). 
Much research has translated changes in average temperature on a daily, seasonal, or annual basis into heating-degree-days $(H D D)^{3}$, which are then used in energy simulation models to project demand for space-heating (Wilkoks \& alii, 2008, p. 73). We follow the same approach to investigate the links between rising regional temperature and global energy use. The POLES model already estimates energy-heating demand by fuel type (oil, gas, biomass and electricity) driven by fuel prices and building surfaces, the latter depending positively on per capita GDP. We add to this heating demand the variation in HDD for each year, compared to the HDD of the base year (2010), with a temperature elasticity $(\alpha)$ provided by the literature ${ }^{4}$. From the initial heating demand (HDEM, for country $C$ and fuel $F$ ), we estimate heating demand with the impact of climate change (HDEMCC, for country $\mathrm{C}$ and fuel F) as below:

$$
\operatorname{HDEMCC}_{[\mathrm{C}, \mathrm{F}]}=\operatorname{HDEM} M_{[C, F]} *\left(\frac{\operatorname{HDD}}{\operatorname{HDD}_{2010}}\right)^{\alpha}
$$

The same methodology is used for the tertiary sector. The impact of temperature changes on residential or tertiary energy consumption can be measured as the difference in energy consumption taking into account climate change, or not. Multiplying the absolute impacts by the average energy price for heating in the residential or tertiary sectors in the relevant region yields the variation in energy costs associated with the impacts of climate change. The average energy price of heating is calculated as the weighted average of prices and quantities of substitutable energies used for heating in the residential or tertiary sectors in each region, while taking into account systemic effects and feedbacks on price and demand levels.

\subsubsection{Modelling the impacts of climate change on the cooling demand}

An important impact of higher summer temperatures in many European countries will be the accelerated growth of electricity consumption for space-cooling, with significant impacts on peak electricity demand in the summer. However, few papers propose a clear methodology to measure these effects. McNeil and Letschert (2007) were the first to propose an appropriate approach to this issue. Isaack and van Vuuren (2009) developed this approach further in their paper on "Modelling global residential sector energy use for heating and air conditioning in the context of climate Change" and we applied their propositions in the framework of the POLES model. Firstly, we model the changes in air-conditioner ownership and secondly average unit energy consumption for a typical benchmark equipment.

- Average air conditioning equipment rate $\left(A C E R_{[C]}\right.$, for country $\left.C\right)$ is obtained by multiplying air-conditioning availability (AVRES $[\mathrm{C}]$ ) by the climate maximum saturation rate (CMAX $\left.\mathrm{CC}_{[\mathrm{C}]}\right)$.

$$
\operatorname{ACER}_{[C]}=\operatorname{AVRES}_{[C]} * C M A X_{[C]}
$$

\footnotetext{
${ }^{3}$ The Heating-Degree-Day (HDD) variable is based on the number of degrees Celsius by which the daily mean temperature ((the maximum temperature on day $\mathrm{i}$ - the minimum temperature on day $\mathrm{i}) / 2$ ) falls below $18 \stackrel{ }{\circ} \mathrm{C}$. The HDD values are added up for all the days in the year when the mean temperature falls below $18 \stackrel{\circ}{ } \mathrm{C}$.

${ }^{4} \square=1.8$ in our case
} 
- Residential Air Conditioning Availability $\left(\mathrm{AVRES}_{[C]}\right)$ is dependent on revenue following a logistic S-curve:

$$
\operatorname{AVRES}_{[C]}=\frac{1}{\left(1+\mathrm{e}^{\left.(3.78) * \mathrm{e}^{-0.23^{*} \text { GPPOP }_{[C]}}\right)}\right.}
$$

- Climate maximum saturation depends on the heating-degree-days (CDD) ${ }^{5}$.

$$
\mathrm{CMAX}_{[\mathrm{C}]}=1-0.95 * \exp \left(-0.0019 * \mathrm{CDD} 2010_{[\mathrm{C}]}\right)
$$

- Air-conditioning unit energy consumption per square metre $\left(\mathrm{ACUEC}_{[C]}\right)$ depends on heating-degree-days, but there is a significant dependence on income too. Based on the Morna Isaac and Detlef Van Vuuren equation and data collected from the literature, we propose the following equation.

$$
\operatorname{ACUEC}_{[c, t]}=\operatorname{ACUEC}_{[c, t-1]]} * \frac{\operatorname{CDD}_{[t]}}{\operatorname{CDD}_{[t-1]}} * \frac{\left(a * \ln \left(\operatorname{GDPPOP}_{[\mathrm{t}]}\right)+b\right)}{\left(\mathrm{a} * \ln \left(\operatorname{GDPPOP}_{[\mathrm{t}-1]}\right)+b\right)}
$$

Where: $a=7.27 * 10^{-0.8}, \quad b=8.74 * 10^{-0.5}$

The logarithm takes into account saturation effects for high income levels. Finally electricity consumption for space-cooling is obtained by multiplying residential surfaces (RESSURF), calculated endogenously by the model, with average air conditioning equipment rates and air-conditioning unit energy consumption per square metre.

$$
\mathrm{ECOOL}_{[C]}=\operatorname{RESSURF}_{[C]}{ }^{*} \operatorname{ACER}_{[C]} * \operatorname{ACUEC}_{[C]}
$$

The assessment of the energy costs associated with the impacts of climate warming on heating and cooling energy demand results from the multiplication of the absolute impacts on energy consumption (in tonne-oil-equivalent) with the average energy price of energy inputs for heating or cooling in the residential and tertiary sector estimated endogenously by the POLES model (in real value, undiscounted).

\subsubsection{Modelling the impacts of climate change on nuclear and conventional thermal power generation}

Climate change is likely to constrain thermal electricity generation in the 21st century by degrading cooling capability and power-plant efficiency. Conventional thermal and nuclear power stations are major users of water cooling and ongoing maintenance. The amount of water used for power plant cooling also varies according to each plant's electricity generating technology and size. For example, nuclear reactors require the largest amount of water for cooling, followed by baseload fossil fuel power plants.

\footnotetext{
${ }^{5}$ The Cooling-Degree-Day (CDD) variable is based on energy needed for cooling. To derive it, the number of degrees Celsius by which the daily mean temperature exceeds $18{ }^{\circ} \mathrm{C}$ is calculated for every day of the year and added up for all corresponding days of the year.
} 
Thermoelectric power generation will also be vulnerable to fluctuations in the quantity of water supply. "While there is uncertainty in the nature and amount of change in water availability in specific locations, there is agreement among climate models that there will be a redistribution of water as well as changes in the availability by season" (Wilbanks $\&$ alii., 2008). Historically, summertime weather extremes have forced thermoelectric units to be throttled back or shut down to comply with environmental or safety limits on water temperature. Thermoelectric power plants also become less efficient as the ambient air temperature increases.

The effects of higher temperatures on power plants have received much attention in the last years (S zolnoky et al. (1997) ; Mohseni \& Stefan (1999) ; Durmayaz et al. (2006); Förster \& Lilliestam (2009)). All these studies emphasize that two different temperature effects influence the output of thermal power plants: one is the availability factor, the other is the generation efficiency of power plants. The POLES model allows for both these effects, using temperature values supplied by East Anglia University, together with assumptions for efficiency changes based on the literature. Durmayaz et al. (2006), roughly estimate that "the impact of $1^{\circ} \mathrm{C}$ increase in the temperature of the coolant extracted from environment is predicted to yield a decrease of about $0.12-0.45 \%$ in the power output and the thermal efficiency of the pressurized-water reactor nuclear-power plant". It is also necessary to derive river temperatures from air temperatures. Mohseni \& Stefan (1999) propose some linear regressions of stream temperature versus air temperature in order to assess the impact of higher air temperatures on water temperatures in rivers.

Two intermediary variables are calculated to take into account the impact of climate change on availability (coefficient applied to the availability factor, $\mathrm{CTACAF}_{[\mathrm{C}]}$ ) and on the efficiency of thermal technologies (coefficient applied to efficiency, $C T A C E F_{[c]}$ ). The impacts on availability and efficiency are calculated as a function of the impact of a $1^{\circ} \mathrm{C}$ increase in the temperature of the coolant drawn from the environment, of the variation in heating-degree-days, and the coefficient which derives the river temperature from air temperature.

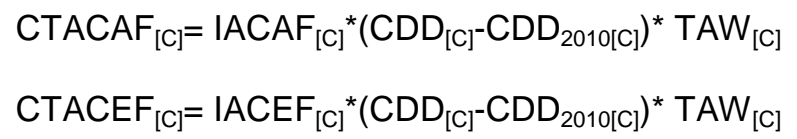

where:

$\operatorname{TAW}_{[\mathrm{C}]}\left(0.7\right.$ in our case $\left.{ }^{6}\right)$ is the change in river temperatures due to a $1^{\circ} \mathrm{C}$ variation in air temperature.

and $I A C A F_{[C, T]}$ and $I A C E F_{[C, T]}$ are the impacts of $a 1^{\circ} \mathrm{C}$ increase in the temperature of the coolant drawn from the environment on the availability and efficiency of thermal power plants of technology $T$.

The resulting availability and efficiency values for thermal technologies are therefore:

\footnotetext{
${ }^{6}$ J ean C. Morrill, Roger C. Bales and Martha H Conklin find that an increase in water temperature of about 0.6$0.8^{\circ} \mathrm{C}$ for every $1^{\circ} \mathrm{C}$ increase in air temperature.
} 


$$
\begin{aligned}
& \operatorname{ACAFCC}_{[C, T]}=\operatorname{ACAF}_{[C, T]} *\left(1-\operatorname{CTACAF}_{[C]}\right) \\
& \operatorname{ACEFCC}_{[C, T]}=\operatorname{ACEF}_{[C, T]} *\left(1-\operatorname{CTACEF}_{[C]}\right)
\end{aligned}
$$

\subsubsection{Modelling the impact of climate change on hydropower generation}

Climate change will also have an impact on hydropower plants. Factors such as the timing and geographical patterns of precipitations, temperatures, evaporation or snow-melt affect stream flow and reservoir levels. While precipitation changes may vary, depending on the geographical area and season, evaporation is expected to rise everywhere due to higher temperatures. Hence, considerable changes in discharge regimes are expected for the future as a consequence of climate change. Moreover, not all national electricity systems are equally affected, because some are more reliant on hydroelectricity than others.

Our study was a first attempt to take into account some of climate change impacts. We do'nt claim to provide a complete explanation of the subject. Indeed evaporative water loss from the reservoir surfaces is an important factor but it is very difficult to measure. Evaporation relies not only on temperature increase but also on wind speeds, humidity and solar radiation and the importance of each of these drivers is regionally dependent. There is no easy way to disaggregate on a national level the end uses for hydroelectric dam water into irrigation, flood control, municipal water, and thermoelectric power plant cooling. Direct measurements of evaporation are scarce, and different evaporation calculation equations give different estimates of absolute evaporation rates and sensitivity to change. Therefore, it can be very difficult to compare results from different studies. For all these reasons the estimation of the impact of the climate change on the evaporative water loss from reservoir surfaces is beyond the scope of this paper. We did not found any estimation of how does it affect the results. This may be subject for further studies in the future.

In order to account for the future climate change impacts on hydroelectricity, we rely on information about changing hydropower potentials available in the literature (Lehner et al. (2005) for European countries), and on the changes in the precipitations as provided by East Anglia University. Lehner et al. (2005) estimated the impacts of climate change on hydropower potential for individual countries in the EU. The authors calculated the influence of climate change on gross hydropower potential as well as its impacts on existing hydro capacity.

The change in technical potential due to climate change also affects economic potential and consequently hydroelectricity generation. Two changes consequently had to be made to the POLES model:

a. climate change impacts on the available capacity factor $\left(A C A F C C_{[C]}\right)$ for existing hydropower capacities, enabling the impact in terms of hydro generation to be calculated:

$$
\operatorname{ACAFCC}_{[C]}=\operatorname{ACAF}_{[C]} *\left(\frac{\operatorname{Rain}_{[C]}}{\operatorname{Rain}_{2010[C]}}\right)
$$


b. changes in hydropower technical potential due to the impact of climate change (POTHYDCC $[$ [C] $)$.

$$
\text { POTHYDCC }_{[C]}=\text { POTHYD }_{[C]} *\left(\frac{\operatorname{Rain}_{[C]}}{\operatorname{Rain}_{2010[C]}}\right)
$$

Where: POTHYD $[C]$ is the technical potential of hydropower plants by country in the reference case, precipitations by country $\left(\right.$ rain $_{[\mathrm{C}]}$ ) for each year compared to the base year (rain2010 ${ }_{[C]}$ ) as provided by East Anglia University.

The total impact is calculated as the difference in hydroelectricity production in the version of the model that takes into account the impacts of climate change and the initial model. Finally, the impact of climate change on electricity generation alters the generation mix, which obviously impacts the average production cost of electricity. For that reason, we first estimate the total cost of electricity generation for each country in the scenarios with and without climate impacts. Then the global impact of climate change on thermal, nuclear and hydroelectricty generation is assessed as the difference between these two total electricity generation costs.

Until now there has been no means of estimating the costs of the impact of extreme heat waves and droughts, which may place the most severe climate-related strains on the electricity sector. During a heat wave, electricity demand on the hottest days - when an overstressed energy sector could be a critical issue, with local grids operating at the limits of their capacity simply because of the many air-conditioning units operating simultaneously. At the same time supply maybe limited by insufficient availability of coolant. Heat waves and droughts (both expected to become more common, according to the IPCC) may in these situations of shortage push the costs of electricity well beyond the costs included in our model.

\subsection{Data and methodology}

To calculate the shifts in energy supply and demand caused by the impacts of changes in heating and cooling demand, two elements are needed: regional data on temperature and precipitation, and a model to convert changes in temperature and precipitations, respectively, into heating or cooling requirements, and nuclear and hydroelectric electricity generation.

To assess these effects, the existing POLES demand model has been improved to allow for heating-degree-days (HDD), heating-degree-days (CDD), changes in precipitation obtained from the High Resolution Gridded Dataset of the Climate Research Unit at University of East Anglia and from the Tyndall Centre for Climate Change Research, as part of world-energy trends described in two emission scenarios of the IPCC Special Report on Emission Scenarios (SRES, Nakicenovic et al. 2000).

The first one is the SRES A1B scenario, a medium-high emission scenario, based on the IPCC A1 storyline with a future world of rapid economic growth, new and more efficient technologies and strong convergence between regions. The A1B scenario adopts a balanced contribution by the various energy sources (fossil and renewable), with comparable technological changes in the energy 
system. This scenario has been extensively used in recent EU regional climate modelling studies, notably in the Ensembles ${ }^{7}$ study. For this reason, it has also been used in the ClimateCost project. It reflects a medium-high emission trajectory and leads to long term (2100) median estimates for global average surface temperature increases of about $3.5^{\circ} \mathrm{C}$ relative to pre-industrial levels.

The second case is the Ensembles E1 scenario (van der Linden et al. 2009; Lowe et al., 2009), a mitigation scenario leading to low emissions and long-term stabilization at $450 \mathrm{ppm} \mathrm{CO}_{2}$ eq. It would thus limit global warming to less than $2^{\circ} \mathrm{C}$ with a reasonable degree of probability. Furthermore, the study has integrated uncertainty by considering about 10 alternative climate model outputs for each of these scenarios.

\section{Results and discussion}

\subsection{Impacts of climate change on heating and cooling energy demand in the European residential and tertiary sector}

\subsubsection{Impacts of climate change on heating demand}

In the European Union 37\% of all final energy is consumed in buildings by households and the commercial and tertiary sectors and more than half of this energy $(57 \%)$ is used for heating. According to the initial POLES simulations, which do not consider temperature levels and variations (see figure 2, black columns - BL A1B), EU27 energy demand for heating in the residential sector is expected to decrease because of fuel-price increases, energy-efficiency policies (separate from climate concerns) and technology improvements. As can be expected, the decrease in energy consumption is greater in the climate mitigation scenario (down $60 \%$ in $E 1$ ), because of the higher carbon value, than in the case without mitigation (down 33\% in A1B). Comparison of this heating demand (black columns) with other simulation runs which take into account HDD variation (see various grey columns), shows an even larger decrease in energy consumption. The gap between them (represented by the black area at the top) corresponds to the impact of climate change on heatingenergy demand. As expected, the relative impact is much more important in the scenario without mitigation policies (i.e. A1B). The margins of uncertainty however enlarge in time, from -15 to $-35 \%$ by 2100 at European level for A1B scenarios and from -2\% to $-24 \%$ for $E 1$ scenarios. The impacts in the tertiary sector, are slightly more important in absolute figures, but comparable in relative terms.

\footnotetext{
${ }^{7}$ The Ensembles project is supported by the European Commission under the 6th Framework Programme 2002-2006. Ensembles uses the collective expertise of 66 institutes to produce a reliable quantitative risk assessment of long-term climate change and its impacts.
} 
Figure 2: EU27 heating consumption in the residential sector in A1B and E1 scenarios (baseline compared to various sets of climate change data) ${ }^{8}$

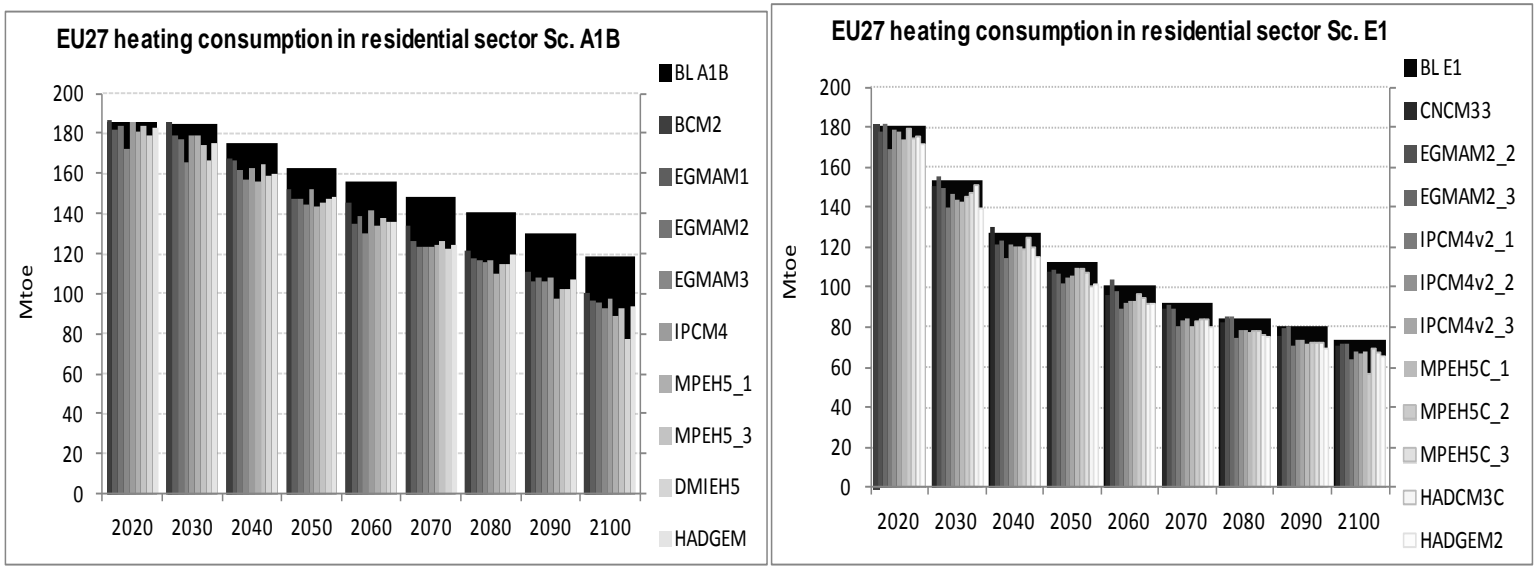

Source: POLES model, PACTE - pôle EDDEN, Climate Cost project

Climate impacts on heating demand vary widely between regions. The impact on residential heating consumption in the western part of the EU (referred to as western Europe here) is greater than elsewhere: in the $A 1 B$ scenarios, respectively two, three and more than four times greater than in southern, northern and eastern EU countries in 2100. Also the impact is greater in the A1B scenarios than in the E1 scenarios. For instance, in western Europe the impact is twice as high in the $A 1 B$ scenarios than in the E1 scenarios. The impact and corresponding gap strongly increases during the period in the A1B scenarios, while it is more limited in the E1 scenarios.

\footnotetext{
${ }^{8}$ In this graph $B L A 1 B$ and $B L E 1$ show projections of heating consumption for POLES runs without taking into account climate change ; BC2M2, EGMAM1, EGMAM2, EGMAM3, IPCM4, MPEH5_1, MPEH5_3, DMIEH5, HAGEM are alternative results with HDD from climate models for A1B scenario; CNCM33, EGMAM2-2, EGMAM2-3, IPCM4v2_1, IPCM4v2_2, IPCM4v2_3, MPEH5C_1, MPEH5C_2, MPEH5C_3, HADCM3C, HADGEM2 are results with HDD of climate models runs for E1 scenario. Similar presentation has been applied for other following graphs with and without taking into account of the climate change.
} 
Figure 3: EU27 climate impacts on heating consumption in residential sector in A1B scenario by region

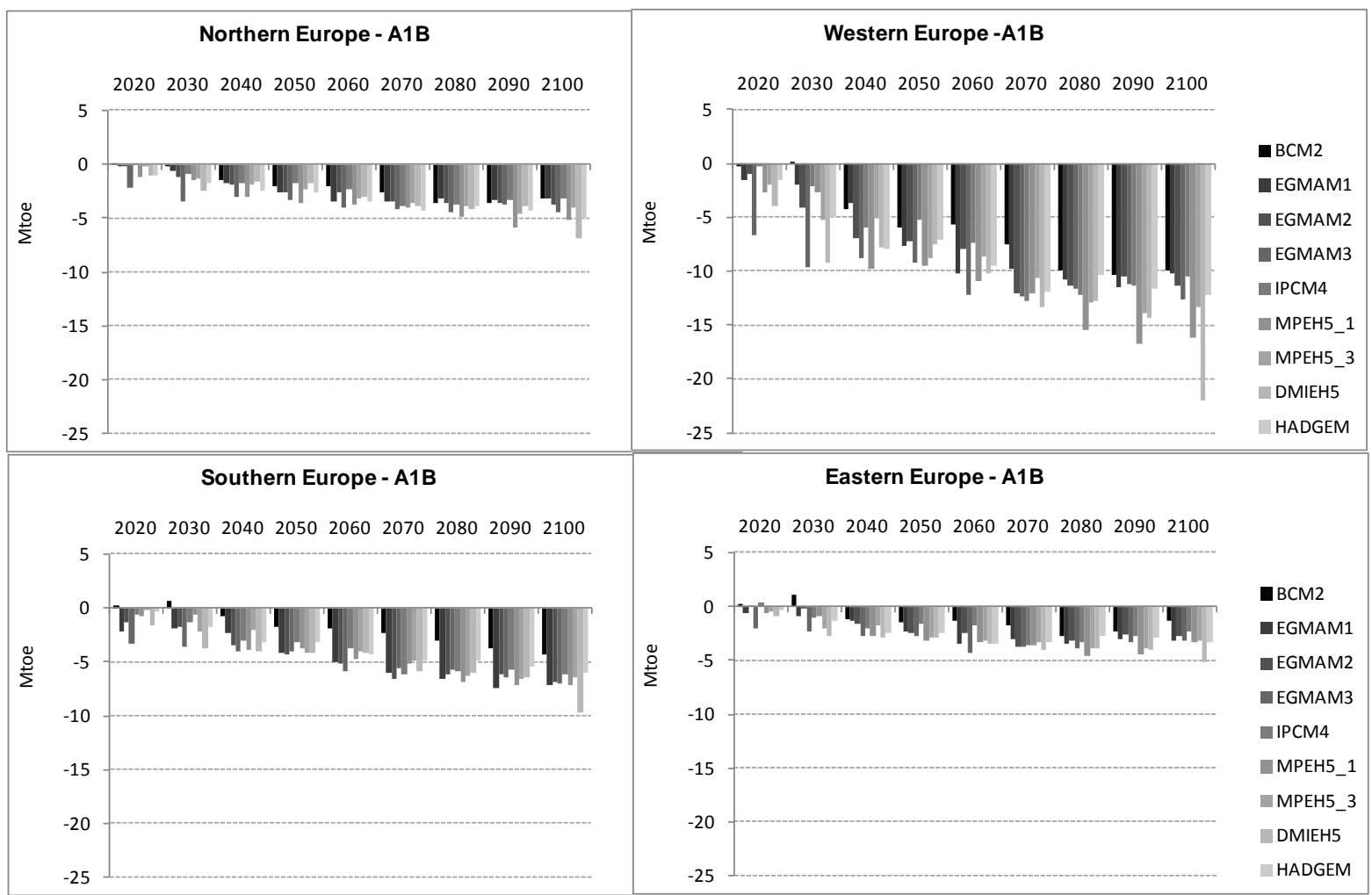

Source: POLES model, PACTE - pôle EDDEN, Climate Cost project

\subsubsection{Climate change impacts on electricity use for space-cooling}

So far, in most European countries, the amount of energy required for heating has been much greater than the energy used for space-cooling. The EU air-conditioning market is much smaller than in the United States and J apan. In the US and J apan 65\% and $85 \%$ respectively of households are fitted with air-conditioning, compared with only $5 \%$ in Europe. The corresponding figures for commercial buildings are $80 \%$ in the US, $100 \%$ in Japan and $27 \%$ in Europe ${ }^{9}$. However, due to increasingly frequent heat waves, rising demand for comfort, improved affordability and more efficient air-cooling products, air-conditioning uptake is rising fast in Europe. This rapid diffusion is expected to accelerate with climate change. At the same time the efficiency and affordability of cooling devices is improving.

Energy statistics in many countries fail to distinguish electricity used for cooling. This may have not been a problem in the past due to the relative insignificance of cooling in terms of the total energy delivered in some regions. But it certainly is now and will remain so. Good quality data is essential for improving short and long-term projections of demand for energy to cool or heat buildings.

Residential cooling-energy demand in Europe is projected to increase rapidly, mostly driven by the increase in cooling degree-days and equipment rates. As a result, in the A1B scenario EU27

\footnotetext{
${ }^{9}$ Source: High Efficiency and Low Environmental Impact Air Conditioning Systems, Centre for Energy Studies; France, 2003
} 
electricity use for space-cooling, when climate change is taken into account, is expected to increase by about $3 \%$ per year through the century (see Figure 4, grey columns). According to the climate projections used in our study, analysis shows a wide variation in increases ranging from $13 \%$ to $85 \%$ in 2050, and up to twice as much in 2100 for the A1B scenarios with climate change (compared to the $A 1 B$ scenario without impacts of climate change). The gap between the two simulations is much smaller in the E1 scenario. In the low-mitigation scenarios, due to a low initial level in air-conditioning equipment and high expected increase in cooling degree-days, a large increase in electricity demand for residential cooling is to be expected.

In the tertiary sector cooling-electricity demand is expected to increase by a factor of almost four in the A1B scenario from 2020 to the end of the period, even when the impacts of climate change are not taken into account. Of course, cooling-electricity demand is higher in the scenarios which do take into account climate change (see Figure 4, bottom graphs) but relatively speaking the impact is less significant than in the residential sector.

\section{scenarios}

Figure 4: EU27 cooling consumption in residential and tertiary sector in A1B and E1

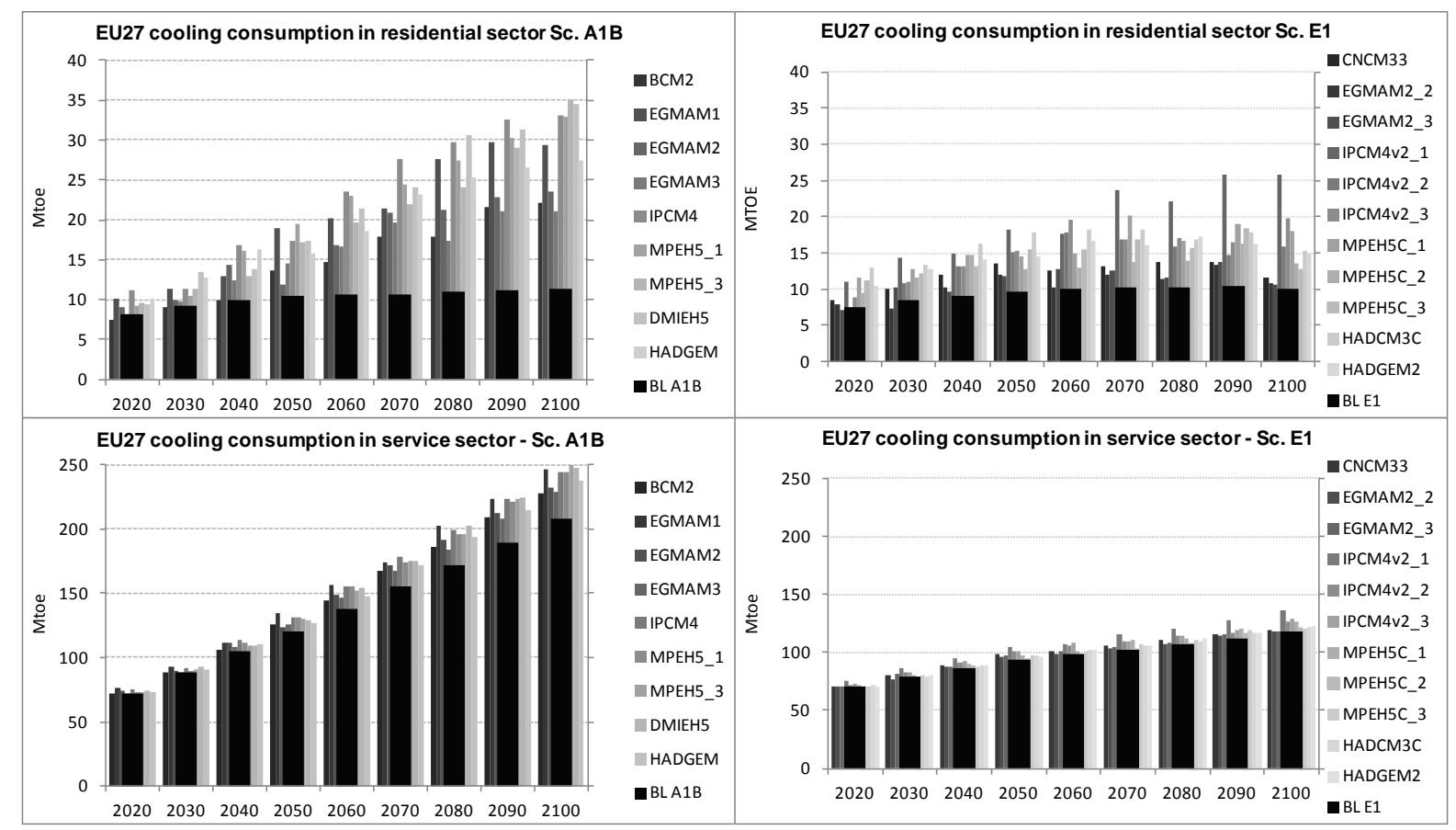

Source:

POLES model, PACTE - pôle EDDEN, Climate Cost project

As may be expected, the impacts vary from region to region within the EU. Figure 5 shows the evolution of the impact of climate change on energy consumption estimates for space-cooling in the residential sector, by region, in the A1B scenarios, compared with the baseline without impacts. Western and southern Europe are the most impacted regions. The impact on peak-electricity demand in the summer may be significant in southern European countries, but in the absence of suitable data availability we were unable to quantify this impact in the present study. 
Figure 5: Impact of climate change and increase in EU27 electricity consumption for space-cooling in the residential sector by region in the A1B scenario

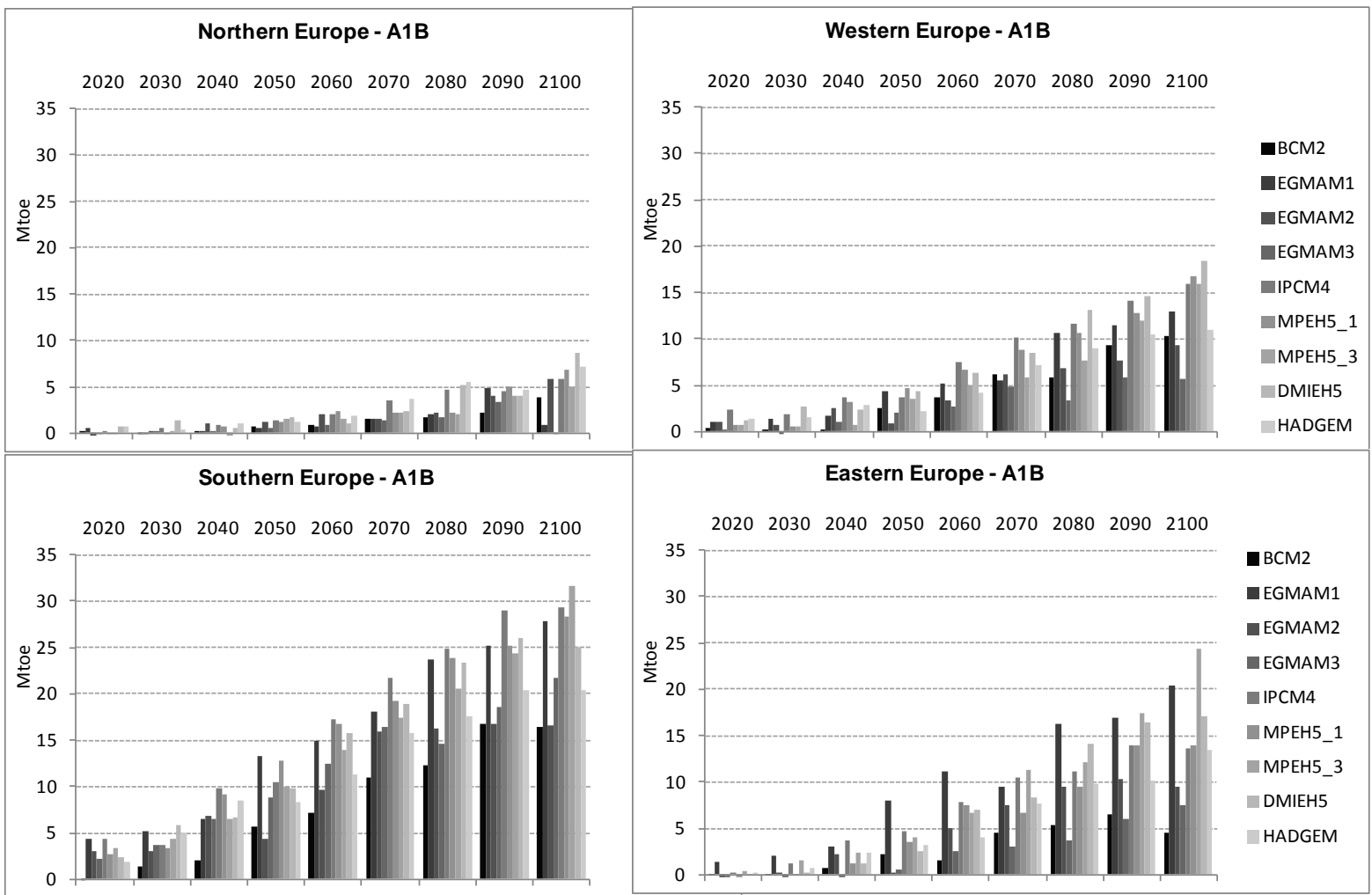

Source:

POLES model, PACTE - pôle EDDEN, Climate Cost project ${ }^{10}$

\subsection{Climate change impacts on the energy supply}

Climate change could potentially influence most electricity generation technologies. Air and water temperatures, as well as rainfall may adversely affect electrical generation efficiencies particularly for nuclear and fossil-based thermal generation and for hydroelectric power plants. In some cases water scarcity may even alter new power plant investment decisions. The most direct climate impacts are related to water availability for power-plant cooling, as drought conditions may seriously jeopardize energy production. The amount of water used for nuclear and conventional thermal power plant cooling varies depending on the specific generating technology and size. Nuclear reactors, for example, require large amounts of water for cooling, followed by baseload fossil-fuel power plants.

\footnotetext{
${ }^{10}$ western Europe : Austria, Belgium, France, Germany, Luxembourg, Netherlands, S witzerland. northern Europe : Denmark, Estonia, Finland, Iceland, Ireland, Latvia, Lithuania, Norway, Sweden, United Kingdom southern Europe : Albania, Bosnia and Herzegovina, Croatia, Greece, Italy, Macedonia, Malta, Portugal, Slovenia, Spain, Yugoslavia

eastern Europe : Bulgaria, Cezch Rep., Hungary, Poland, Romania, Slovakia
} 
"W hile there is uncertainty in the nature and amount of change in water availability in specific locations, there is agreement among climate models that there will be a redistribution of water as well as changes in the availability by season" (Wilbanks \& alii., 2008). In recent years, summertime weather extremes have already required several thermoelectric units to be throttled back or shut down, to comply with environmental or safety limits on water temperature. Rising temperatures and lower river levels may reduce the efficiency of thermal power plants, due to pumps consuming more power to maintain the desired condensing temperatures, or shifts from wet to dry-cooling tower systems (Förster, 2009). Climate change is thus likely to further constrain thermoelectric generation in the 21st century, by degrading cooling capability and power-plant efficiency. It is worth recalling that the problem may be exacerbated by the likely combination of these effects with periods of high demand for cooling (Com, 2009).

Hydropower plants will also be affected by climate change. Factors such as the timing and geographical pattern of precipitations, temperature or snow-melt will affect stream flows and reservoir levels. At the same time scanty or heavy rain may hinder or boost hydropower generation, depending on the geographical area and season. In all cases evaporation is expected to rise due to higher temperatures, thus limiting the production potential. Hence, considerable changes in discharge regimes are expected for the future as a consequence of climate change. Moreover, not all countries are equally affected because some are more reliant on hydroelectricity than others.

\subsubsection{Climate change impacts on nuclear and conventional thermal generation}

Without taking into account the impacts of the climate change conventional thermal and nuclear power stations supply more than $85 \%$ of the electricity in the EU. Although this share is expected to fall to about $70 \%$ in $A 1 B$ and $60 \%$ in E1 by 2100 , their output may reach $6,000 \mathrm{TWh}$ in $A 1 B$ and 3,600 TWh in E1 (see Figure 6), respectively 2.5 and 1.3 times current thermal production.

Figure 6: EU27 electricity production and mix (2000-2100)

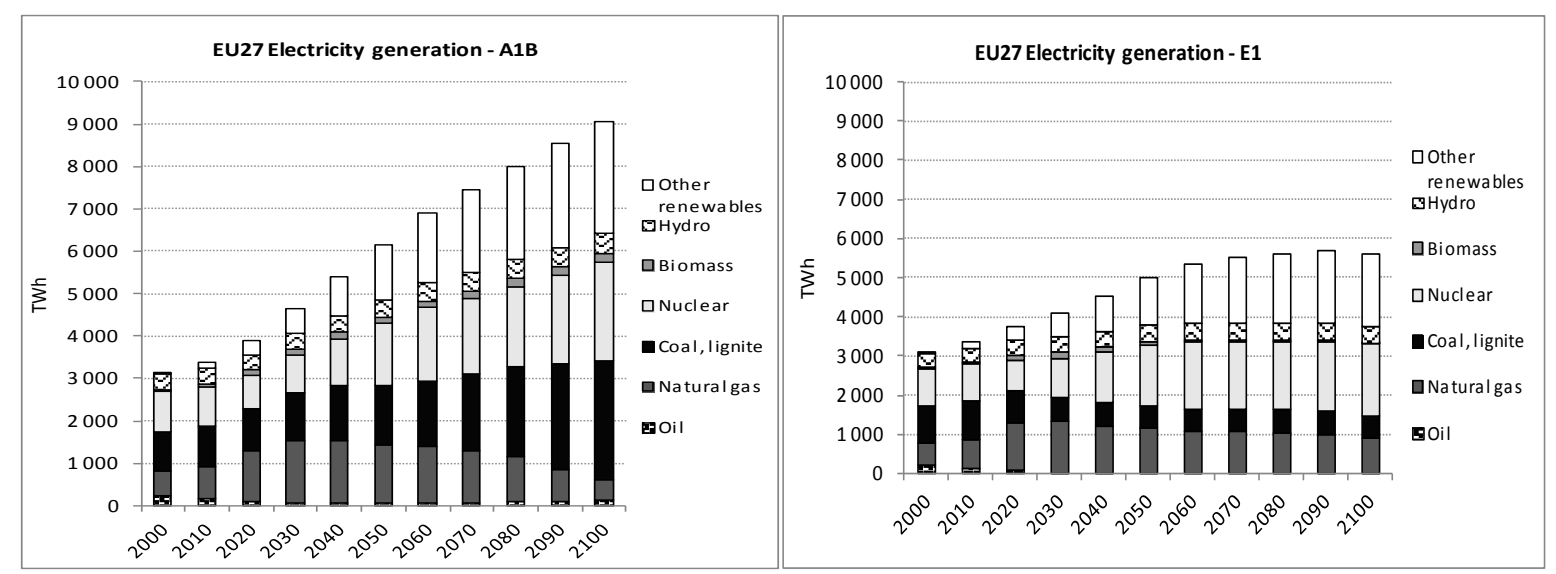




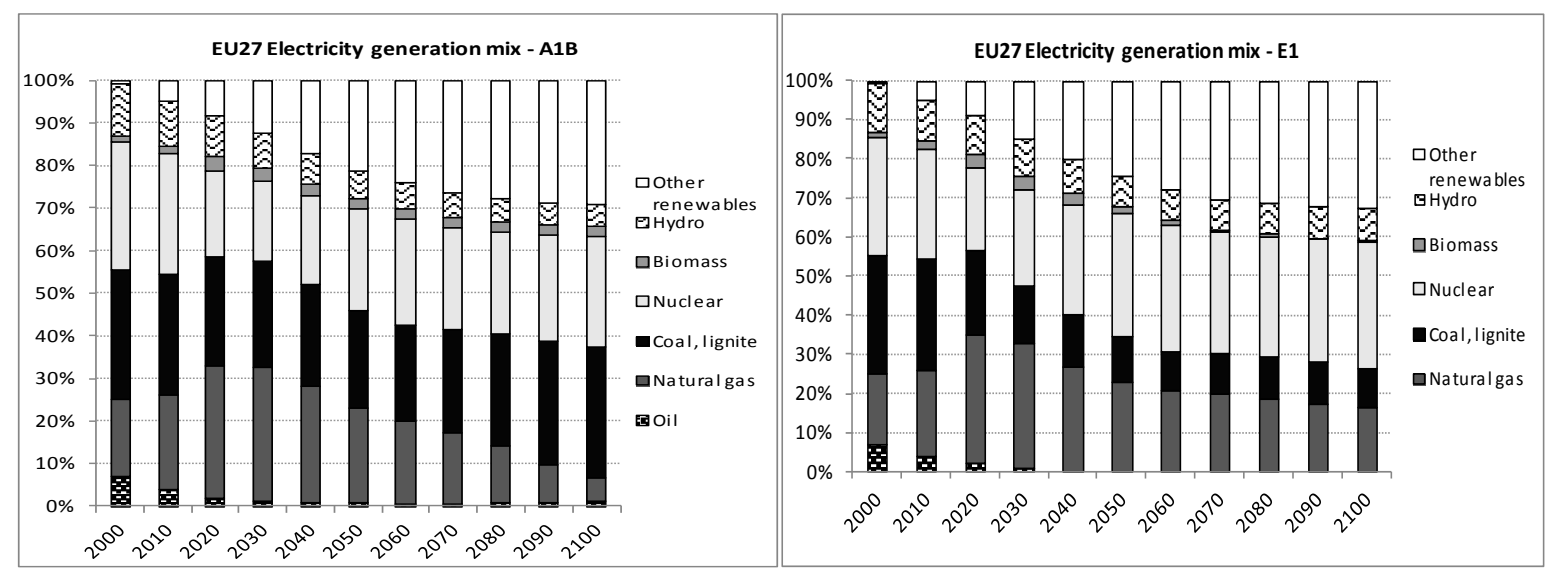

Source: POLES model, PACTE - pôle EDDEN, Climate Cost project

However, at this stage, these projections do not take account of higher river temperatures, lower stream flows, heat waves and higher temperatures associated with climate change, all of which are expected to place considerable strains on the thermal power sector, reducing efficiency and raising electricity costs. Signs of these changes are increasingly jeopardizing nuclear power reliability. In France, for instance, where 0.02 cubic kilometres of water are drawn annually to cool nuclear facilities, heat waves in 2003 caused a shutdown or reduction of output in 17 plants, forcing the nation to import electricity at more than 10 times the normal cost (Ackerman and ali. 2008).

Simulations which take into account higher air and water temperatures due to climate change show that fossil-based thermal and nuclear power generation could potentially be constrained, by as much as $2-3 \%$ and $4-5 \%$ of annual production, respectively. This means 150 TWh per year less due to higher temperatures in the $A 1 B$ scenarios. The results below indicate divergence from the future baseline due to climate change (see Figure 7). This amount corresponds to the production of about 20 nuclear plants, which is far from negligible.

Figure 7: Impact of climate change on EU27 energy supply in the A1B scenarios

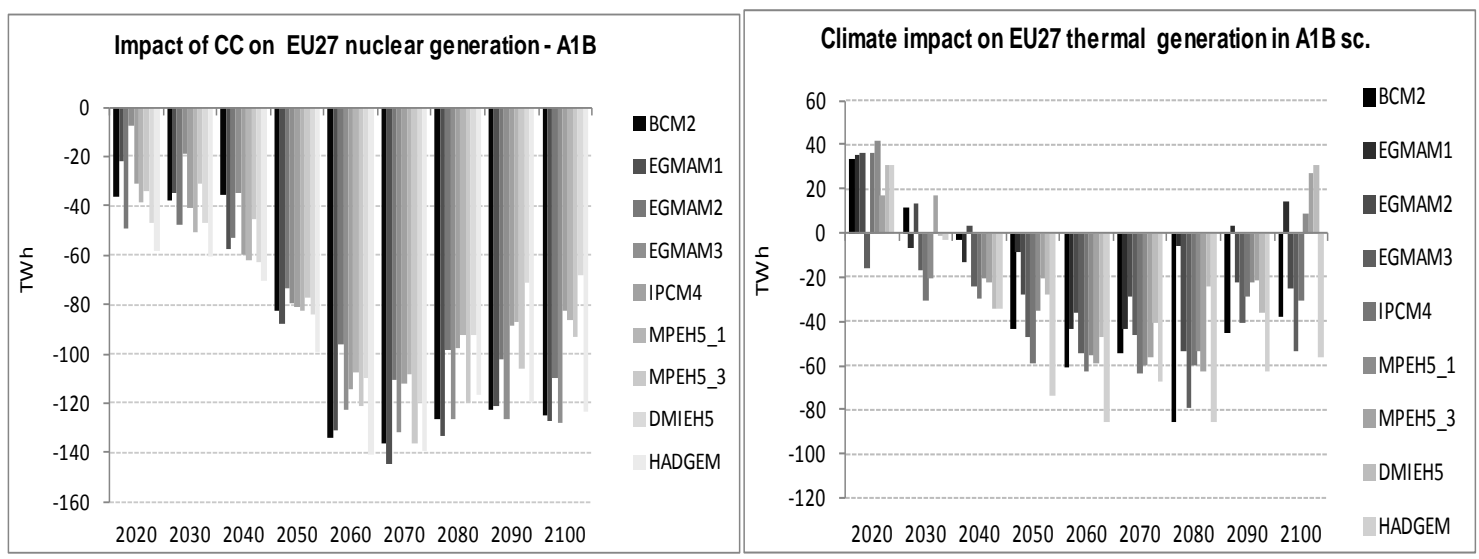

Source:

POLES model, PACTE - pôle EDDEN, Climate Cost project

The profiles obviously differ significantly between countries as the signs of future warming vary across the EU. Western and southern European countries are projected to see greater warming, 
more extreme seasonal patterns, with greater summer increases. Similar patterns are found for precipitations, with decreases predicted in regions already suffering from water scarcity ${ }^{11}$.

\subsubsection{Climate change impacts on hydropower generation}

While hydroelectric power is expected to be an important source of renewable electricity growth in a context of low-carbon energy policies, changes in discharge and rising temperatures will impact hydrology in each region and affect hydro-electricity generation. Precipitation may vary, increasing or decreasing depending on the region and season, but evaporation is expected to rise in all cases, due to higher temperatures (Christensen et al., 2011). In the EU hydropower now makes up about $10 \%$ of total installed capacity, generating 352 TWh in 2010 , and there is strong motivation to raise this capacity to 465 TWh by 2100 , especially in southern and eastern Europe.

When the impacts of climate change on the technical potential of hydroelectricity generation are taken into account in POLES, significant consequences for the level of hydro generation are apparent. It has not been possible to analyse precipitation, surface run-off, river flow and water withdrawals differentiated by season in detail at catchment level, but only variations in average annual precipitation obtained from climate models. Some indicative estimates of the potential scale of impacts in the future EU electricity system have nevertheless been identified. The results vary strongly according to the climate models (see Figure 8 ), due to the various models predicting very contrasting shifts in precipitation. At a global level, the A1B scenario results show an overall decrease in EU European hydro-generation due to climate change of around $3 \%$ in 2050 and $8 \%$ in 2100 , compared to the baseline case without climate-change impacts. The impacts are lower for the E1 scenario with respectively down about 2 and $3 \%$.

Figure 8: Impact of climate change on EU27 hydroelectricity generation

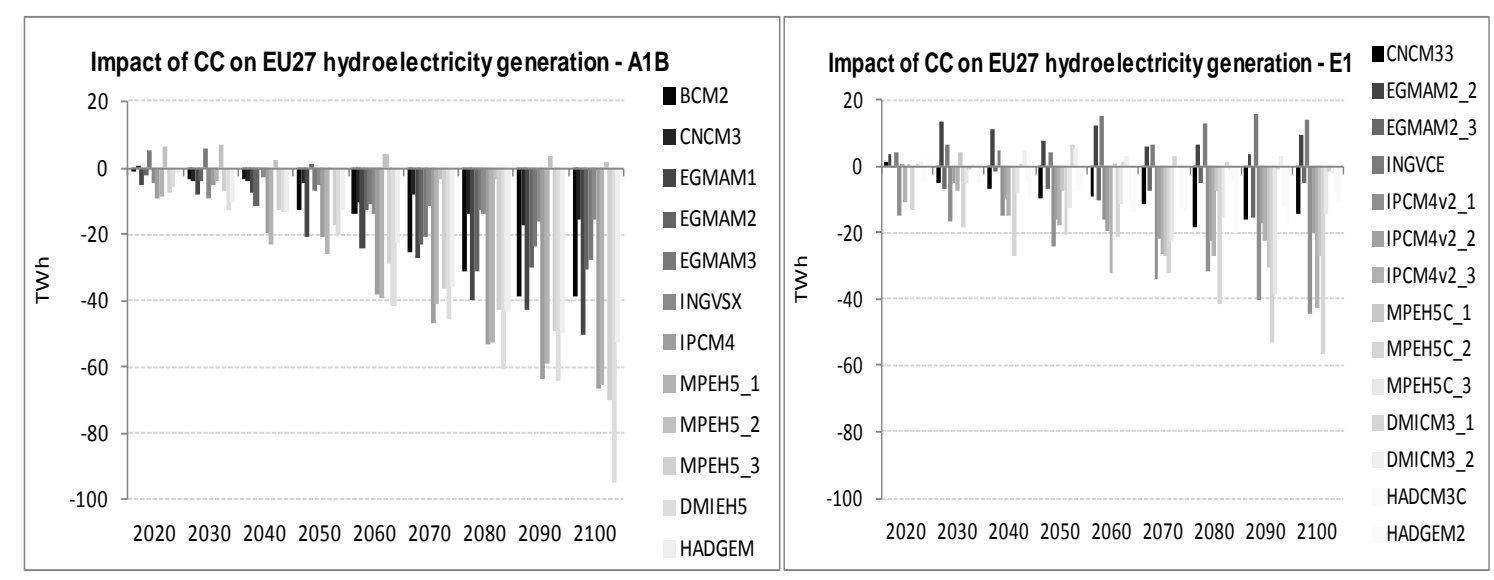

Source:

POLES model, PACTE - pôle EDDEN, Climate Cost project

\footnotetext{
${ }^{11}$ Note that impacts of future extremes, as heavy precipitation events, heat-waves, possible changes in storms or future sea level rise have not been taken into account in this study.
} 
For estimating the aggregated impact of climate change on EU27 energy supply in A1B and E1 scenarios we show in the Figure 9 the mean of the impacts of corresponding climate model projections on nuclear, thermal and hydroelectricity generation. In the A1B and E1 scenarios climate change impacts on hydroelectric generation amount to about $20 \%$ and $10 \%$, respectively, of the total aggregated impact.

Figure 9: Aggregated impact of climate change on EU27 energy supply in A1B and E 1 scenarios
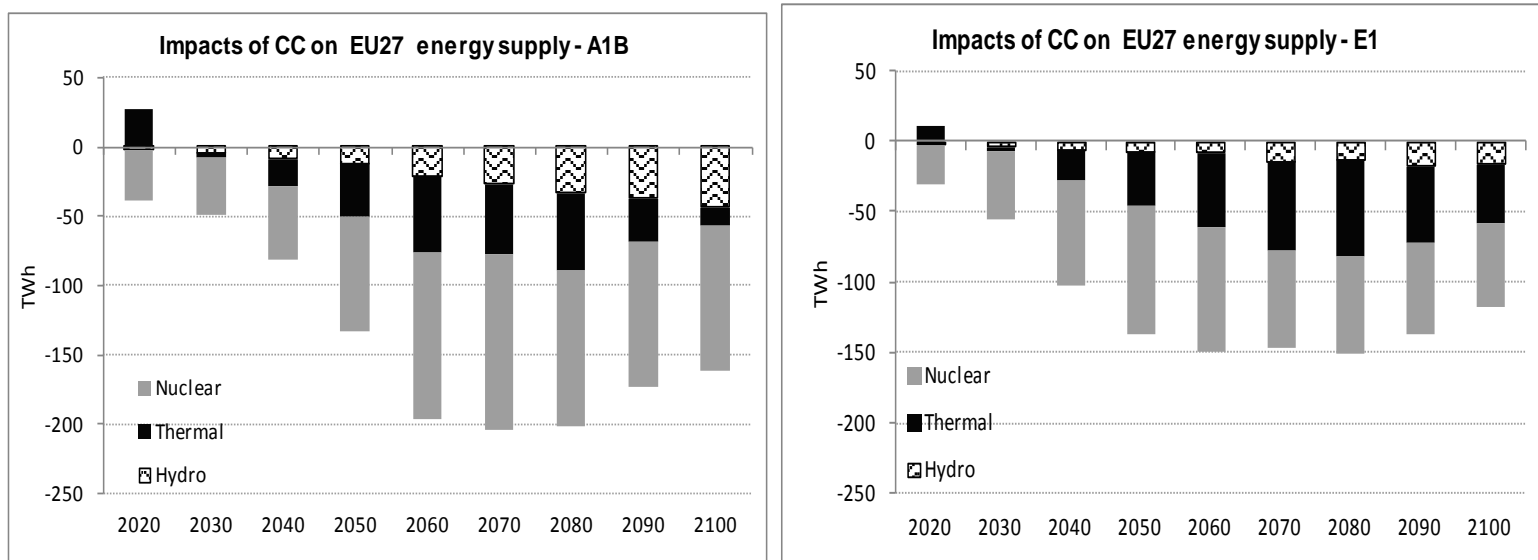

POLES model, PACTE - pôle EDDEN, Climate Cost project

The impacts vary depending on the region. Results indicate decreasing discharge volumes for southern, eastern and central Europe, falling by more than $20 \%$ in some countries, whereas the projected increases in discharge volumes for northern European countries may at times exceed $20 \%$. This analysis makes no allowance for annual variability. Regarding specific countries, the French power-generation system seems the most impacted in the EU, losing about 40 TWh per year, equivalent to the output of five new nuclear power plants. This would need to be replaced somehow. Italy, the United Kingdom and Poland form a second group of severely affected countries, with a drop of about 20 TWh per year due to climate change.

Ultimately the impact of climate change on electricity generation will alter the generation mix, which will obviously affect the average production cost of electricity. We have consequently started by estimating the total cost of electricity generation for each country in the baseline scenarios without climate impacts, and then with impacts. The cost of climate change through changing conditions for thermal, nuclear and hydroelectricity generation can then be assessed as the difference between the two total electricity generation costs.

\subsection{Overview of total climate-change impact on energy supply and demand}

Taken globally, aggregation of climate-change impacts on the energy sector, as estimated in this paper, shows mixed effects. For example, on the demand side, electricity demand for cooling in the EU27 in the A1B scenario is expected to increase by more than 50 Mtoe by 2100 , whereas 
heating demand is expected to decrease by about $65 \mathrm{M}$ toe per year by 2100 (see Figure 10). It should be noted that comparison of the energy quantities consumed - less for heating and more for cooling may hide impacts associated with the different nature of the energy carriers involved, respectively electricity and heating fuels. Under the E1 scenario, in which both the reduction in heating and the increase in cooling-energy are lower, the net effect is of course much lower than in the A1B scenario.

Due to higher temperatures and lower precipitations, nuclear, thermal and hydro generation will be constrained compared to the corresponding scenarios without climate-change impacts. The highest decrease of around 200 TWh is estimated to occur in 2070 for the A1B scenario and with a 150 TWh drop in 2060 and 2080 in the E1 scenario, whereas the impacts somehow decrease during the following period. The impacts of energy supply and demand cannot be aggregated, being different in nature, but the graphs on the right hand side of Figure 10 do show that the fall in electricity generation due to climate change is greater than the shifts in energy demand, even when the increase in electricity consumption for cooling is separated from the reduction in heating demand. Again, one should also bear in mind that there are substantial variations across the various climate-model runs considered and sizable differences even in the signs of the net effects across the EU.

Figure 10: Climate-change impacts on EU27 energy supply and demand in the A1B and $E 1$ scenarios (with average of climate impact scenarios)

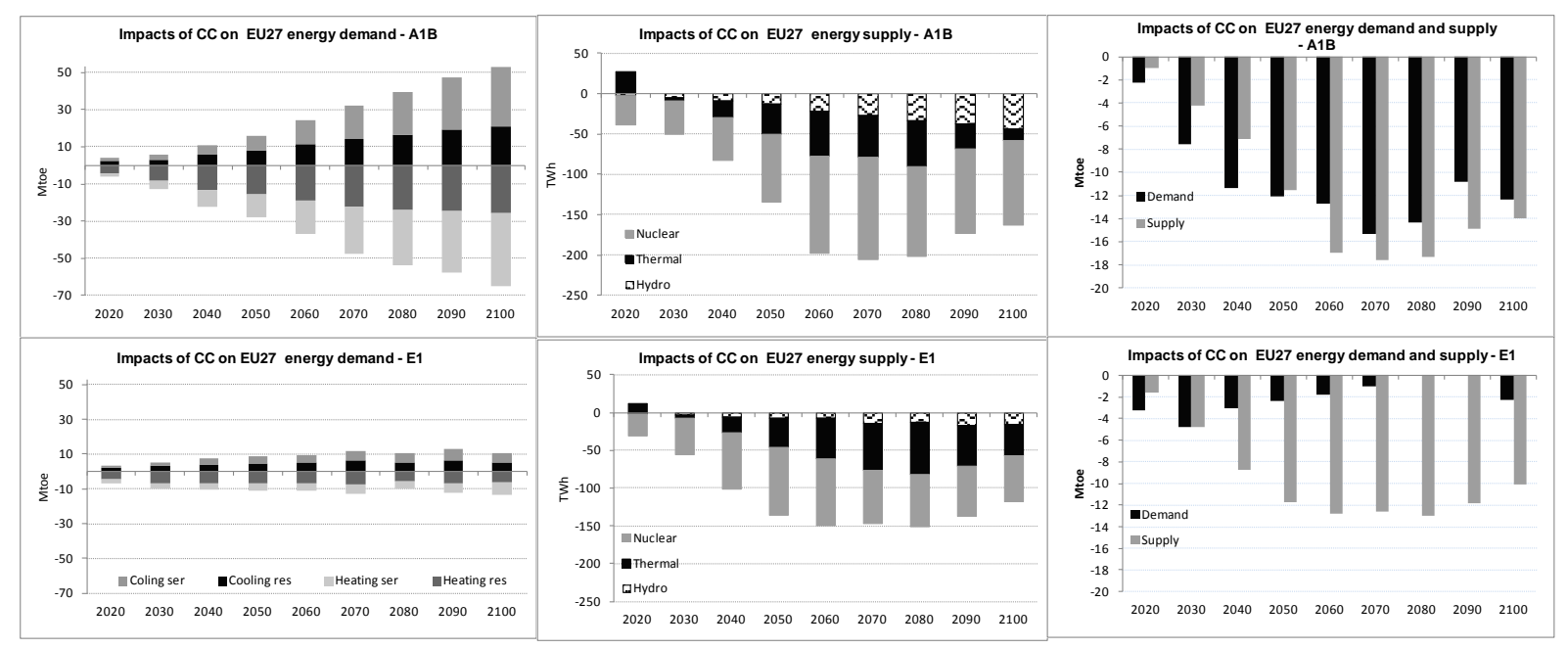

Source:

POLES model, PACTE - pôle EDDEN, Climate Cost project

On a regional basis, the results for western Europe show that its heating consumption is more significantly impacted than elsewhere. Regarding the impact on cooling, it is more substantial in western and southern European countries (see Figure 11). The net effects of climate change on overall energy use remain limited; in all the regions except southern Europe, increases in cooling are more than compensated for by decreases in heating. 


\section{Figure 11: Climate-change impacts on energy demand in the A1B scenario by European region}

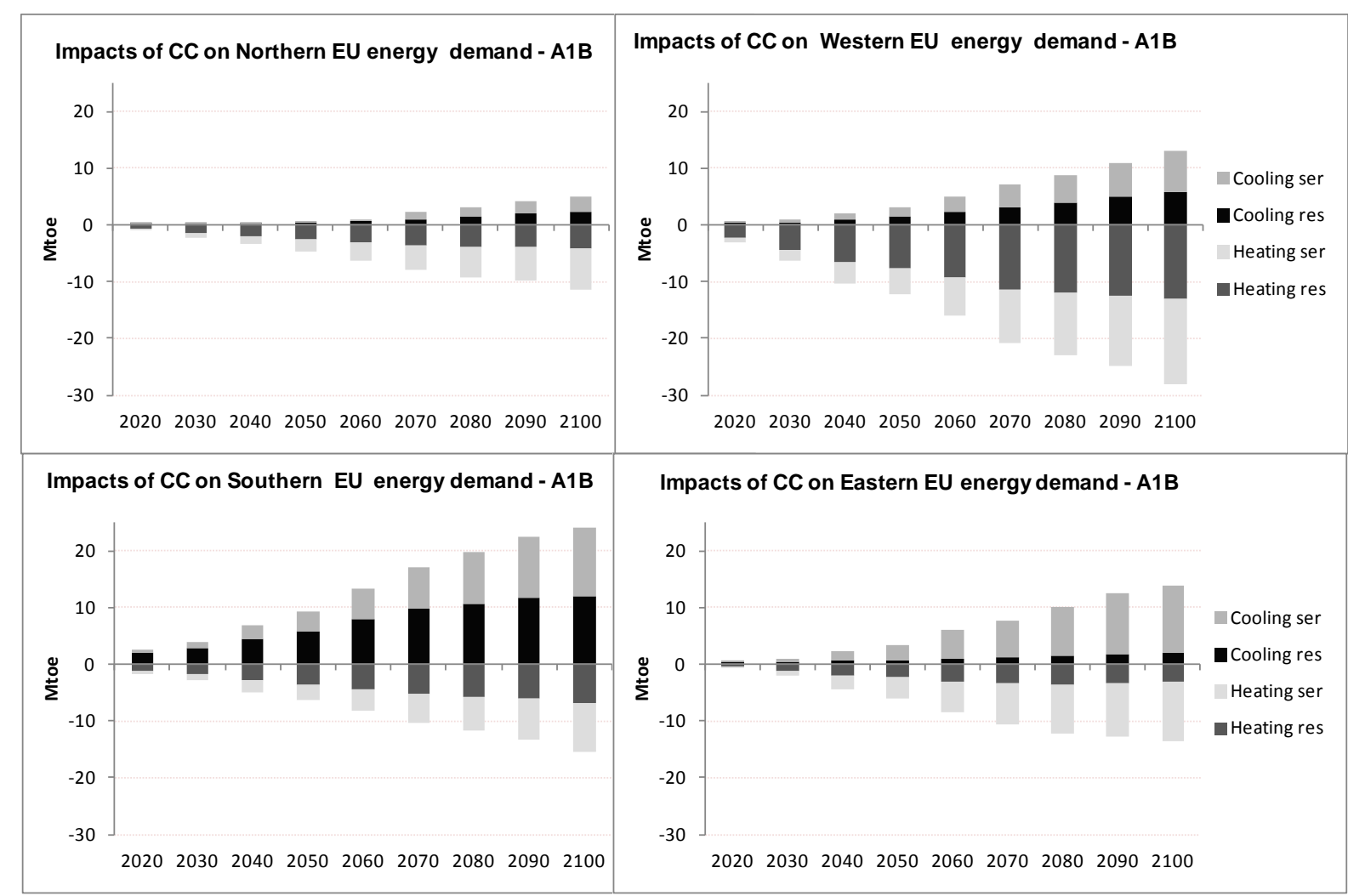

Source:

POLES model, PACTE - pôle EDDEN, Climate Cost project

The results show limited potential positive and negative effects in terms of the cost of energy consumption (consumption $\mathrm{x}$ prices) or total production costs. To assess the net effects of the impacts, we present both of them in the same graph (see Figure 12). The right hand graphs show the aggregate impacts on energy consumption costs, those in the middle the impacts on the supply side, and on the right the total impact. The greatest impact is apparent on the demand side, where warmer conditions lead to a $\$ 140$ billion drop in EU27 heating expenditure corresponding to about $0.17 \%$ of projected EU27 GDP in 2100.

However the costs of additional electricity consumption for air-conditioning in the residential and tertiary sector rise to about $\$ 130$ billion in EU27 by the end of the period (corresponding to $0.16 \%$ of projected EU27 GDP). To this energy cost should be added the investment costs for new air conditioners ( $\$ 7$ billion). The corresponding costs are lower in the E1 scenario. We should emphasize that changes in annual energy costs either for heating or cooling, will not translate symmetrically into changes in equipment costs for heating or cooling: "those who enjoy decreased heating requirements cannot sell part of their existing furnaces (at best, there will be gradual decreases in heating system costs in new structures); on the other hand, those who have an increased need for cooling will buy additional air conditioners at once" (Ackerman \& Stanton, 2008, p. 13). 
The total impact costs, including supply side (about $\$ 100$ billion in 2100 ) are estimated to increase by more $\$ 90$ billion (see right graphs of Figure 12 ) representing $0.11 \%$ of projected EU GDP.

Figure 12: Assessment of economic costs associated with climate-change impacts on EU27 energy supply and demand in the A1B and E 1 scenarios

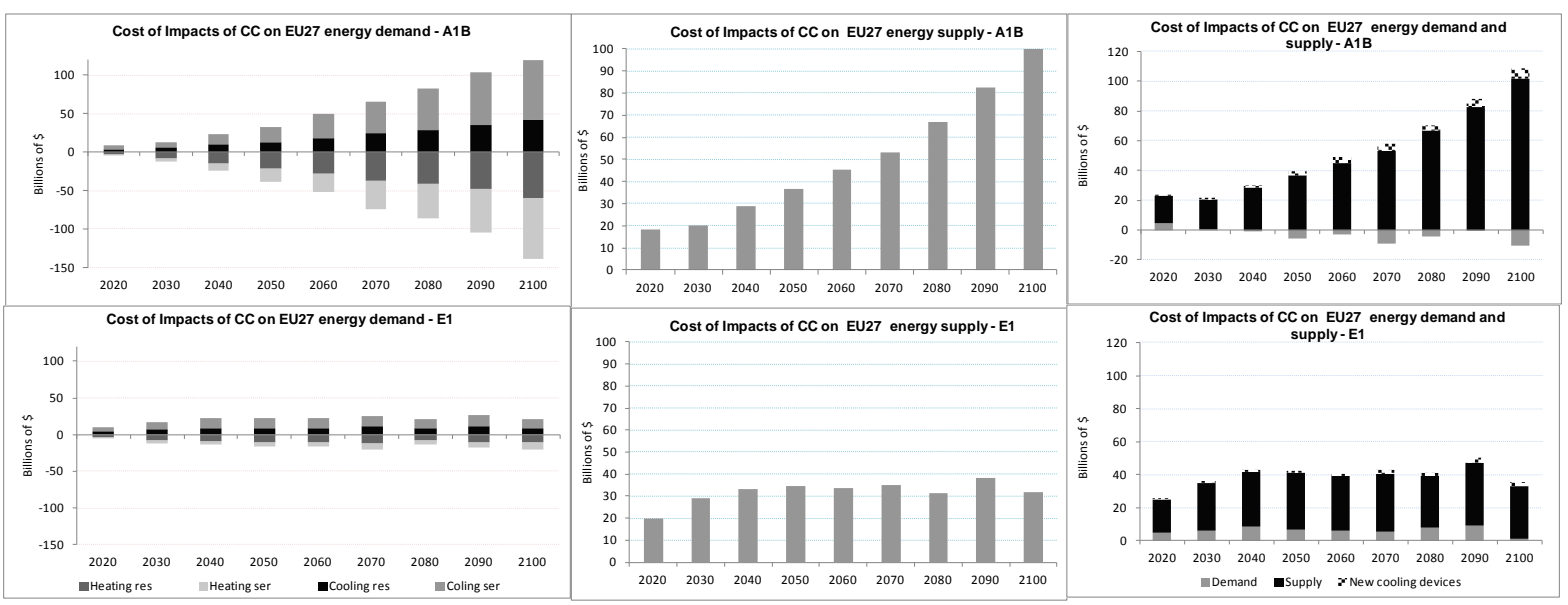

Source:

POLES model, PACTE - pôle EDDEN, Climate Cost project

These values also do not take into account additional factors such as "urban heat island" effects in major European cities, which may further increase cooling demand. These are an important omission and could significantly change cooling demand patterns in the EU. These changes are also important in relation to mitigation policy; indeed, this is probably the single most important area for adaptation-mitigation linkages with potential positive feedbacks, i.e. rising cooling for adaptation inducing an increase in emissions or the reverse of a mitigation action, especially when the electricity required for cooling is even more carbon-intensive than the energy used for heating (e.g. gas, oil). There are also important cross-sectoral linkages with the health impacts of climate change and heat events, as well as wider comfort levels. For the time being it is impossible to estimate the cost of the impact of more frequent heat waves and droughts, which may push electricity costs far beyond the costs usually simulated in the model during periods of shortage.

The study shows that 'net' impacts for Europe are slight. However, some distributional effects appear between the northern and southern regions of Europe. Expenditure for a heating decrease of about $0.6 \%$ of corresponding projected GDP in western and southern Europe, and $0.5 \%$ of GDP in eastern and northern Europe by 2100 for the A1B scenario. In the E1 scenario these costs vary between a $0.2 \%$ drop and a $0.25 \%$ increase depending on the region. In contrast southern countries are the most impacted for space-cooling as they are expected to spend an extra $0.3 \%$ of GDP in 2100 for that purpose.

\section{Conclusions and further research}

The results of the modelling, scenario development and analyses presented in this paper are highly preliminary and remain uncertain. However they do provide the basis for an initial assessment, 
with sufficient detail, of the main impacts to be expected from climate change on the energy system in the European Union. Substantial work has been done with a soft link between the POLES model and the results of 10 climate models in order to quantify the most important impacts of climate change on energy supply and demand, by European country and region. No comparable work has yet been done to assess, in the same study, possible long-term effects of climate change: i) on heating and cooling in the residential and tertiary sectors; ii) on cooling constraints for nuclear and combustion-based thermal generation; and iii) on hydroelectricity generation.

The outlook shows that global warming will impact both the supply and demand side of EU energy: higher temperatures will mean more energy for air-conditioning, up about $50 \mathrm{M}$ toe by 2100 in the A1B scenarios, and less heating for consumers, down by about 65 Mtoe per year by 2100 with a net negative effect of climate change on energy demand by the end of the period, notwithstanding the change in the nature of demand, from heating fuel to cooling electricity. Operating conditions for electric power plants will also be more difficult and expensive, resulting in lower output by thermal, nuclear and hydro-power plants with a maximum loss of about $200 \mathrm{TWh}$ in 2070 for the A1B scenario and 150 TWh in 2060 and 2080 for the E 1 scenario.

The results obtained also provide a first assessment of the costs of the impacts of climate change on the EU energy system. Energy expenditure on the demand side will decrease by $\$ 140$ billion in the EU 27 by 2100 under the A1B scenario for heating and increase by $\$ 136$ billion for space cooling. One important implication of these findings, for the economic impacts of climate change, concerns households, which would benefit from lower spending on heating energy. This will consequently decrease the incentives to invest into dwelling insulation. Overall the additional energy spent on cooling is less than the energy saved due to lower demand for heating; however the amount varies widely by region. There is a strong variation of the effects across Europe. The non-linear patterns are more pronounced in cold countries, such as Norway, where the net effect of temperature increases reduces total energy demand. In relatively mild countries, like Italy, higher demand for electricity during the summer is compensated by lower demand for gas, oil products and coal in winter and spring. In warm countries, such as Spain, the cooling effect increases energy demand. There is also a strong distributional pattern of the results from different climate models, revealing that the potential costs vary by $+/-25 \%$ for the A1B scenario (2100), and could still be significant under a mitigation scenario, with high increases projected from the warmer models.

On the supply side, climate change is likely to affect all renewable energy sources. Biomass potential may be positively impacted by higher temperatures and atmospheric $\mathrm{CO}_{2}$ concentrations in moderate climates, but negatively by reduced water availability or extreme events in some regions. Changes in cloud cover may negatively influence the efficiency of photovoltaic plants. Whereas increasing average wind velocities may improve the electricity output of wind power plants (however, the extent of increasing wind velocities for Europe is still unknown), higher frequencies of serious storms may negatively affect total annual wind-power generation and even destroy wind turbines, cutting power output. But assessment is difficult and these impacts need further investigation. 
However the impacts of expected changes in average temperature rise, or precipitation and hydrological regimes can already be considered for thermal power and hydro power generation. Our estimates are based on average regional climate changes, for temperature and precipitation. They show a decrease of European hydro generation due to climate change of around 3\% in 2050 and $8 \%$ in 2100 , compared to the case without climate change. Furthermore, the results estimate that thermal and nuclear power generation could be constrained respectively by $2-3 \%$ and $4-5 \%$ per year due to changes in CDD in the A1B scenarios. This type of analysis should be complemented in the future by taking into account extreme events. Indeed the most severe climate strains on the electricity sector will be increasingly intense heat waves. During a heat wave, local grids can be pushed to the limit of their capacity simply by the large number of air-conditioning units operating simultaneously. Heat waves and droughts (both expected to become more common, according to the IPCC) will push the costs of electricity during times of shortage well beyond the costs included in our model. Extreme weather events, including storms, damage electricity transmission lines. The vulnerability of electricity transmission may vary across different countries and regions, depending on the age and type of this infrastructure: aerial or underground cabling (COM 2009). Some efforts are emerging for quantifying increased transmission losses due to temperature rises (Reiter \& Turton, 2010).

The study has considered uncertainty by considering a large range of climate model outputs for $A 1 B$ and E1 scenarios. POLES simulate the complex interactions between energy demand and supply and climate change. Every added complexity, while intended to improve some aspect of simulated energy demand and supply, also introduces new sources of possible error (e.g., via uncertain parameters). Furthermore, despite the progress that has been made in climate models, scientific uncertainty regarding the details of many processes remains. The soft-linkage of the POLES model with climate models is still very rough. Better integration is needed with other climate and hydrological models and many improvements are necessary, such as better representation of the relationship between changes in precipitation and temperature. Obviously the overview of the effects of climate change on the energy sector depend on a large number of very uncertain climate change parameters such as expected changes in average temperature increases, in precipitation amounts or hydrological regimes ${ }^{12}$. Furthermore, the effects depend on a wide range of uncertain factors beyond climate change alone, such as patterns of economic and population growth, technological change.

Finaly, it is necessary also to bear in mind, the limits of modelling either with the POLES model or climate models which are inherently uncertain. The uncertainty in calculations poses strong limitations to the interpretation of the results.

In spite of the remaining uncertainties, this study is a step forward in our understanding of major climate impacts and of their costs for the EU energy system under scenarios that reflect different policy trade-offs in terms of adaptation versus mitigation. It already shows that the low mitigation scenarios involve a higher vulnerability of the EU energy system and particularly its electricity system component.

\footnotetext{
${ }^{12}$ Unexpected and dramatic climate events have not even been taken into account.
} 


\section{Acknowledgement}

The authors acknowledge the support of the ClimateCost (Full Costs of Climate Change) Collaborative project funded by the European Commission under the Seventh Framework Programme, in carrying out this research and East Anglia University for making climate simulation data available for coupling with the POLES model. We also thank two anonymous referees and an Associate Editor whose suggestions and remarks have greatly helped us to improve the quality of the manuscript. 


\section{References}

1. Ackerman, F., Stanton, E., 2008, The Cost of Climate Change: What We'll Pay if Global Warming Continues Unchecked, Natural Resources Defense Council, New-York.

2. Adnot, J., coord., 1999, Energy Efficiency of Room Air-Conditioners (EERAC), Final Commission of the European Communities. DG Energy, Brussels.

3. Akpinar-Ferrand, E., Singh, A., 2010, Modelling increased demand of energy for air conditioners and consequent $\mathrm{CO} 2$ emissions to minimize health risks due to climate change in India, Environmental S cience \& Policy 1, 702-712.

4. Alcamo, J., Flörke, M., Märker, M., 2007, Future long-term changes in global water resources driven by socioeconomic and climatic changes, Hydrological Sciences J ournal 52, 247-275.

5. Anderson, J., Bassi, S., Dworak, T., et al., 2008, Potential impacts of desalination development on energy consumption, Institute for European Environmental Policy, London.

6. Arnell, N., 1996, Global Warming, River Flows and Water Resources, J. Wiley, Chichester.

7. Christensen, O. B, Goodess, C. M. Harris, I, and Watkiss, P. (2011). European and Global Climate Change Projections: Discussion of Climate Change Model Outputs, Scenarios and Uncertainty in the EC RTD ClimateCost Project. In Watkiss, P (E ditor), 2011. The ClimateCost Project. Final Report. Volume 1: Europe. Published by the Stockholm Environment Institute, S weden, 2011. ISBN 978-91-86125-35-6.

8. Criqui P., Mima S. (2006), POLES model - State of the Art, http://lepii.upmfgrenoble.fr/spip.php? article113.

9. De Cian, E., Lanzi, E., Roson, R., 2007, The Impact of Temperature Change on Energy Demand: A Dynamic Panel Analysis, FEEM Nota Di Lavoro 46, Fondazione Eni Enrico Mattei, Milan.

10. Dupont, G., 2009, Eau et énergie ne peuvent pas se passer l'une de l'autre, Le Monde, 29 mars.

11. Durmayaz, A., Sogut Oguz, S., 2006, Influence of cooling water temperature on the efficiency of a pressurized-water reactor nuclear-power plant, International J ournal of Energy Research 30, 799-810.

12. EEA, 2008, Impacts of Europe's changing climate - 2008 indicator-based assessment, Report No 4, European Environment Agency, Copenhagen.

13. EPRI, 2002, Water \& Sustainability (Volume 3): U.S. Water Consumption for Power Production - The Next Half Century, Electric P ower Research Institute, Palo Alto.

14. European Commission, 2009, Commission staff working document accompanying the White paper Adapting to climate change: Towards a European framework for action, Impact Assessment, COM (2009)147 final, 92-93.

15. Förster, H., Lilliestam, J., 2009, Modelling thermoelectric power generation in view of climate change, Regional Environmental Change 10, 327-338.

16. Glicksman, L. R., Norford, L. K., Greden, V., 2001, Energy conservation in chinese residential buildings: Progress and Opportunities in Design and Policy, Annual Review of Energy and the Environment 26, 83-115.

17. Goossens, X., Bonnet, J.F., 2001, Etude de la matrice des interactions eau-énergie. Commissariat Général du Plan, Paris.

18. Harrison, G.P., Whittington, H.W., 2002, Vulnerability of hydropower projects to climate change, IEEE Proceedings Generation, Transmission \& Distribution 149, 249-255.

19. IPCC, 2007, Climate Change 2007: Impacts, Adaptation and Vulnerability, IPCC, Geneva. 
20. Isaac, M., Van Vuuren, D., 2009, Modelling global residential sector energy use for heating and air conditioning in the context of climate Change, Energy Policy 37, 507-521.

21. Karagiannis, I. C, Soldatos, P. G, 2008, Water desalination cost literature: review and assessment, Desalination 223, 448-456.

22. Kenny, F., Barber, N., Hutson, S., Linsey, S., Lovelace, J., Maupin, M., 2009, Estimated Use of Water in the United States in 2005, Circular 1344, U.S. Geological Survey, Reston.

23. Lehner, B., Czisch, G., Vassolo, S., 2005, The impact of global change on the hydropower potential of Europe: a model-based analysis, Energy Policy 33, 839-855.

24. McNeil, M.A., Letschert, V.E., 2007, Future air conditioning energy consumption in developing countries and what can be done about it: the potential of efficiency in the residential sector, In: Saving energy - just do it!, ECEEE 2007 Summer Study proceedings, 1311-1323.

25. Mideksa, T., Kallbekken, S., 2010, The impact of climate change on the electricity market: A review, Energy Policy 38, 3579-3585.

26. Mima S, Criqui $P$, and Watkiss $P$ (2011). The Impacts and Economic Costs of Climate Change on Enery in Europe. Summary of Results from the EC RTD ClimateC ost Project. In Watkiss, P (Editor), 2011. The ClimateCost Project. Final Report. Volume 1: Europe. Published by the Stockholm Environment Institute, Sweden, 2011. ISBN 978-91-8612535-6.

27. Mohseni, O., Stefan, H. G., 1999, Stream temperature/air temperature relationship: a physical interpretation, J ournal of Hydrology 218, 128-141.

28. Nakicenovic, N., Alcamo, J., Davis, G., de Vries, B., Fenhann, J., Gaffin, S., Gregory, K., Grübler, A. et al.: 2000, Special Report on Emissions Scenarios, Working Group III, Intergovernmental Panel on Climate Change (IPCC), Cambridge University Press, Cambridge, UK, 595 pp. (ISBN 052180493 0).

29. National Intelligence Council, 2009, China: The Impact of Climate Change to 2030. A Commissioned Research Report, Washington.

30. National Intelligence Council, 2009, India: The Impact of Climate Change to 2030. A Commissioned Research Report, Washington.

31. Petrick, S., Rehdanz, K., Tol, R., 2010, The Impact of Temperature Changes on Residential Energy Consumption, Kiel Working Paper No. 1618, Kiel Institute for the World Economy.

32. Pilli-Sihvola K., Aatola P., Ollikainen M., Tuomenvirta H., 2010, Climate change and electricity consumption - Witnessing increasing or decreasing use and costs?, Energy Policy 38, 2409-2419.

33. Sailor, D.J . and Pavlova A.A. (2003). Air conditioning market saturation and long-term response of residential cooling energy demand to climate change. Energy, Volume 28, Issue 9, J uly 2003, Pages 941-951.

34. Silander, J., Vehviläinen, B., Niemi, J, et al., 2006, Climate change adaptation for hydrology and water resources, FINADAPT Working Paper 6, Finnish Environment Institute, Helsinki.

35. Sovacool, B.K., Sovacool, K.E., 2009, Identifying future electricity-water tradeoffs in the United States, Energy Policy 37, 2763-2773.

36. Szolnoky, C., Busas, K., Clement, A., 1997, Impacts of the climate change on the operation of a freshwater cooled electric power plant, Periodica Polytechnica. Civil Engineering 41, 71-94.

37. Thivet, G., 2008, Eau/Energie et changement climatique en Méditerranée. In: Changement climatique et énergie en Méditerranée, Plan Bleu, Sophia Antipolis, 530552.

38. Tol R., 2002, Estimates of the Damage Costs of Climate Change, Environmental and Resource Economics 21: 135-160, Kluwer Academic Publishers. Printed in the Netherlands

39. U.S. Department of Energy, 2006, Energy demands on water resources, report to congress on the interdependence of energy and water [available at 
http://www.sandia.gov/energy-water/docs/121-R ptT oC ongress-EW wEIAcomments-

FINAL.pdf]

40. Wilbanks, J. Th., et al., 2008, Effects of climate change production and use in the United States, CCSP, p. 74.

41. W orld Enegy Council, 2007, Hydropower, In: Survey of Energy Resources, 271-313.

42. Zhelezko, Y. S., Kostyushko, V. A., Krylov, S. V., et al., 2004, Power Losses in Electrical Networks depending on weather conditions, Power Technology and Engineering 39, 4248.

43. J ean C. Morrill, Roger C. Bales, and Martha H Conklin, Estimating Stream Temperature from Air Temperature: Implications for Future Water Quality, https://eng.ucmerced.edu/people/rbales/CV/P ubsM/98 